\title{
Significance of congestive heart failure as a cause of pleural effusion: Pilot data from a large multidisciplinary teaching hospital
}

\author{
Piotr Korczyński ${ }^{1}$, Katarzyna Górska ${ }^{1}$, Damian Konopka ${ }^{2}$, \\ Dżamila Al-Haj ${ }^{2}$, Krzysztof J. Filipiak ${ }^{3}$, Rafał Krenke ${ }^{1}$
}

${ }^{1}$ Department of Internal Medicine, Pulmonary Diseases and Allergy, Medical University of Warsaw, Poland ${ }^{2}$ Students' Research Group “Alveolus”, Medical University of Warsaw, Poland

${ }^{3}$ Department of Cardiology, Medical University of Warsaw, Poland

\begin{abstract}
Background: Epidemiological data on the causes of pleural effusion (PE) are scarce. Data on the local prevalence of various causes of PE may play a crucial role in the management strategy of patients with PE. The aim of the study was to investigate the causes of PE and to assess 30-day mortality rate in unselected adult patients treated in a large, multidisciplinary hospital.

Methods: Retrospective analysis of medical records, including chest radiographs, of 2835 consecutive patients admitted to the hospital was performed. Radiograhic signs of PE were found in 195 of 1936 patients in whom chest radigraphs were available. These patients formed the study group.

Results: The leading causes of PE were as follows: congestive heart failure (CHF; 37.4\%), pneumonia (19.5\%), malignancy (15.4\%), liver cirrhosis (4.2\%) and pulmonary embolism. The cause of PE in $6.7 \%$ patients was not established. There was a significant predominance of small volume PE as compared to a moderate or large volume PEs (153, 28 and 14 patients, respectively). Almost $80 \%$ of patients with CHF presented with small volume $P E$, while almost $50 \%$ of patients with malignant $P E$ demonstrated moderate or large volume $P E$. Thirty-day mortality rate ranged from $0 \%$ for tuberculous pleurisy to 40\% for malignant PE (MPE).

Conclusions: Pleural effusion was found in $10.1 \%$ of patients treated in a large multidisciplinary hospital. CHF was the leading cause of PE. Although 30-day mortality in patients with CHF was relatively high, it was lower than that in parapneumonic PE and MPE. (Cardiol J 2020; 27, 3: 254-261)

Key words: epidemiology, pleural effusion, congestive heart failure, pleuritic, pneumonia, tuberculosis, cancer
\end{abstract}

\section{Introduction}

Pleural effusion (PE) affects approximately 1.5 million patients per year in the United States [1]. This condition may be associated with a wide range of underlying diseases, including pneumonia, tuberculous pleurisy, malignancies, chronic heart failure, liver cirrhosis and many other diseases. Therefore, causative diagnosis in patients with
$\mathrm{PE}$ is challenging and often requires not only a thorough clinical assessment but also the use of different imaging techniques, diagnostic thoracentesis with pleural fluid analysis, pleural biopsy and/ /or thoracoscopy. As some of the above procedures are relatively invasive, it is critically important to properly select patients who require comprehensive diagnostics. In this context, epidemiological data on the local prevalence of different causes of

Address for correspondence: Dr. Katarzyna Górska, Department of Internal Medicine, Pulmonary Diseases and Allergy, Medical University of Warsaw, ul. Banacha 1A, 02-097 Warszawa, Poland, tel: +48 2259925 62, fax: +48 225991560 , e-mail: drkpgorska@gmail.com

Received: 29.08.2018 Accepted: 28.10.2018 
PE may play a crucial role in the management strategy of patients with this condition. For instance, a predominance of benign and self-limited underlying diseases questions the necessity of more advanced diagnostic procedures in a significant proportion of patients with $\mathrm{PE}$.

According to data from the United States, the most common cause of $\mathrm{PE}$ was congestive heart failure $(\mathrm{CHF})-36.3 \%$, while the relative incidence of malignant (MPE) and tuberculous pleural effusion (TPE) among all patients with PE was $14.5 \%$ and $0.2 \%$, respectively [1]. In contrast, a retrospective analysis of all patients with $\mathrm{PE}$ who underwent diagnostic thoracentesis over a 19-year period at a university hospital in Spain showed that malignancies and tuberculosis (TB) were responsible for approximately 2 -fold, and 45 -fold higher percentage than those reported in the United States (27.3\% and 9\%, respectively). In one fifth of 3077 patients with PE (20.8\%), $\mathrm{CHF}$ was diagnosed as an underlying disease [2]. It was most prevalent in elderly patients $(45 \%$ of all causes were in patients older than 80 years of age), while TB was the most common etiology in patients $<34$ years of age ( $52 \%$ of all causes of $\mathrm{PE}$ in this age group) [2].

Comparison of the above studies demonstrates that the epidemiological data should be interpreted with caution, as they may show significant local variability. This is because they are affected by a number of factors, such as ethnicity, local burden of different diseases, age structure of the population and the availability and quality of a healthcare system. Tuberculous PE may serve as a good example. There are not only huge regional differences in the incidence rate of TB, but also significant differences in TB manifestations. In regions with low and intermediate $\mathrm{TB}$ incidence, only $2-5 \%$ of all TB patients present with TPE $[3,4]$. On the other hand, in low income and high TB incidence countries the percentage of patients with TPE in TB patients can be as high as $22.8 \%$ and $68.8 \%[5,6]$.

The undeniable progress in healthcare quality over the years has undoubtedly affected epidemiological data. The age adjusted death rate for the leading cause of mortality, i.e. cardiovascular diseases (CVDs), has decreased since 1993. The annual death rate for the second leading cause of mortality, i.e. lung cancer decreased from 91.1 in 1990 to 49.8 in 2015 [7]. Deaths from these two conditions accounted for as many as $45.3 \%$ of all deaths in the United States in 2015 [8].
Cardiovascular diseases have also been a leading cause of death in Poland. For a number of years, nearly half of all deaths have been caused by CVDs. Nonetheless, in the last few decades, a gradual decline in relative death rate from CVDs has been observed. At the same time a change in the relative contribution of deaths associated with coronary artery disease and CHF was noted, with a significant decline for the first and an increase for the latter [9]. Significant changes in the epidemiology of two other common causes of $\mathrm{PE}$, i.e. TB and malignancies were also reported. In Poland, the relative incidence of TB pleurisy decreased from $2.7 \%$ to $1.9 \%$ between 2002 and 2006 and to $0.9 \%$ in 2015 [10]. Mortality due to breast cancer increased from 28.2 to 86.3 per 100,000 between 1980 and 2013. At the same time, lung cancer mortality increased from 29.6 to 56.0 over the same period [11].

According to available research, there are no current data on the etiology of PE effusion in Central and Eastern Europe. Therefore, a pilot study herein was undertaken on the causes of PE in all patients admitted to a large multidisciplinary teaching hospital.

The specific study objectives were as follows: (i) to determine the causes of PE in a non-selected group of patients admitted to a multidisciplinary teaching hospital located in a large urban area; (ii) to assess 30-day mortality in hospitalized patients with PE.

\section{Methods}

This retrospective cross-sectional study was performed at the Central Teaching Hospital of the Medical University of Warsaw, Poland. This is a multidisciplinary hospital with more than 1000 beds which provide medical services on different levels.

The study included all patients admitted to the hospital between January $1^{\text {st }}$ and February $1^{\text {st }}, 2017$. Data were extracted from the Hospital Information System and Picture Archiving and Communication System (PACS). Chest radiographs of all patients were initially analyzed by two medical faculty students to identify all radiographs with radiological signs of PE. The findings were further confirmed by two pulmonologists, who also reviewed other imaging studies (e.g. computed tomography scans and thoracic ultrasound) of these patients. Only patients with pleural effusion confirmed by both pulmonologists were included in further analysis. 


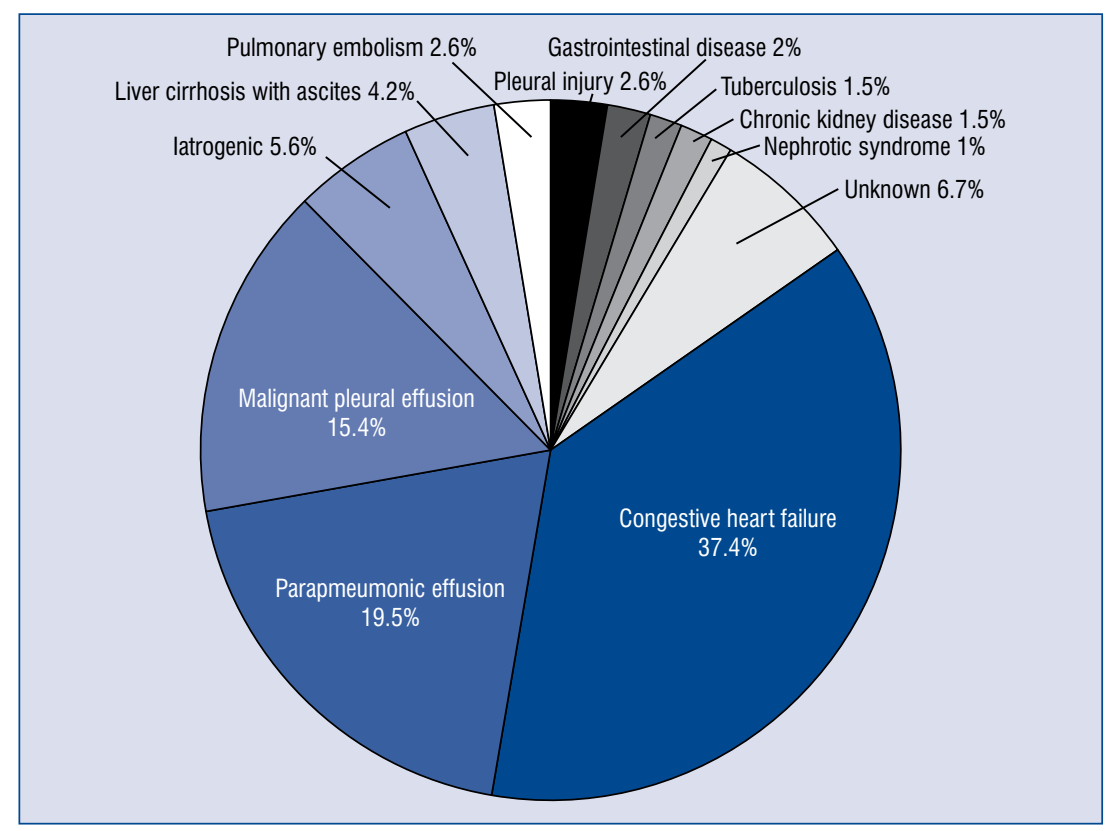

Figure 1. Percentage of patients with various causes of pleural effusion in the investigated group.

Cause of PE was determined by the analysis of medical data and reports, radiology and laboratory findings. Definitions and criteria used for the diagnosis of underlying diseases were consistent with those presented in the previous studies [12, 13]. Patients in whom the available data were insufficient to make a diagnosis, were allocated to the "undiagnosed pleural effusion" group. At the next stage, 30-day mortality was assessed with the date of the first chest radiograph with PE construed as day "zero".

Laterality and semiquantitative assessment of pleural fluid volume were based on chest radiographs performed in the erect position (standing or sitting). Pleural effusions were classified as small when occupied $\leq 1 / 3$ of the ipsilateral hemithorax on plain chest radiograph, moderate when occupied between $1 / 3$ and $2 / 3$ of the hemithorax, and large when occupied more than $2 / 3$ of the hemithorax.

\section{Statistical analysis}

Data are presented as median and interquartile ranges (IQR). The D'Agostino-Pearson test was used to assess normality of data distribution. Differences between continuous variables were tested using the Kruskal-Wallis or Mann-Whitney U test. Categorical variables were expressed as numbers and percentages and were compared using the Fisher exact test. All p values were 2 -tailed and $\mathrm{p}<0.05$ was considered statistically significant.
Statistical analysis was performed with MedCalc statistical software version 18.5 (MedCalc Software bvba, Ostend, Belgium).

\section{Results}

Four thousand one hundred and sixty-eight patients were admitted to the hospital between January $1^{\text {st }}$ and February $1^{\text {st }}, 2017$. Almost $70 \%$ of these patients (2835) were admitted to non-surgical departments, while the remaining patients (1333) were admitted to surgical departments or intensive care unit. Chest radiographs were performed in 1936 patients and in 220 of these, radiographic signs of PE were initially identified. The initial findings were further verified by pulmonary specialists and 195 patients with chest radiographs demonstrating PE were eventually selected.

The most common cause of pleural effusion was heart failure, which accounted for $37.4 \%$ of cases. The second most common cause was parapneumonic effusion (19.5\%) and the third was malignant pleural involvement (15.4\%). Detailed data on PE etiology are presented in Figure 1.

The median age of patients with PE caused by CHF was 80 (IQR 70-87) years and was significantly higher than that of patients with parapneumonic pleural effusion (PPE) and MPE, $\mathrm{p}=0.01$. Thirty-day mortality in CHF was $19.2 \%$, and this percentage was $9.7 \%$ lower than in PPE 
Table 1. Comparative analysis of patients with various causes of pleural exudate.

\begin{tabular}{lccccc}
\hline & PPE $(\mathbf{n}=38)$ & TPE $(\mathbf{n}=3)$ & MPE $(\mathbf{n}=30)$ & Others $(\mathbf{n}=9)$ & P \\
\hline Sex: & $17(44.7 \%) /$ & $3(100 \%) /$ & $14(46.7 \%) /$ & $3(33.3 \%) /$ & 0.2 \\
male/female & $/ 21(55.3 \%)$ & $/ 0(0 \%)$ & $/ 16(53.3 \%)$ & $/ 6(66.7 \%)$ & \\
Age [years]* & $76.5(67-89.3)$ & $44(29.7-50)$ & $70.3(62.25-79.5)$ & $69.9(56-81)$ & $0.014 * *$ \\
30-day mortality & $11(28.9 \%)$ & $0(0 \%)$ & $12(40.0 \%)$ & $1(11.1 \%)$ & 0.27 \\
Affected side: & $10(26.3 \%) / 17$ & $1(33.3 \%) / 2$ & $8(26.7 \%) / 15$ & $1(11.1 \%) / 7$ & 0.6377 \\
L/R/B & $(44.7 \%) / 11(28.9 \%)$ & $(66.6 \%) / 0(0 \%)$ & $(50 \%) / 7(23.3 \%)$ & $(77.8 \%) / 1(11.1 \%)$ & \\
\hline
\end{tabular}

${ }^{*}$ Results presented as median (interquartile range); **Significant difference between PPE vs. TPE $(p=0.024) ; B-$ bilateral; $L-$ left; MPE — malignant pleural effusion; PPE — parapneumonic pleural effusion; R — right; TPE — tuberculous pleural effusion

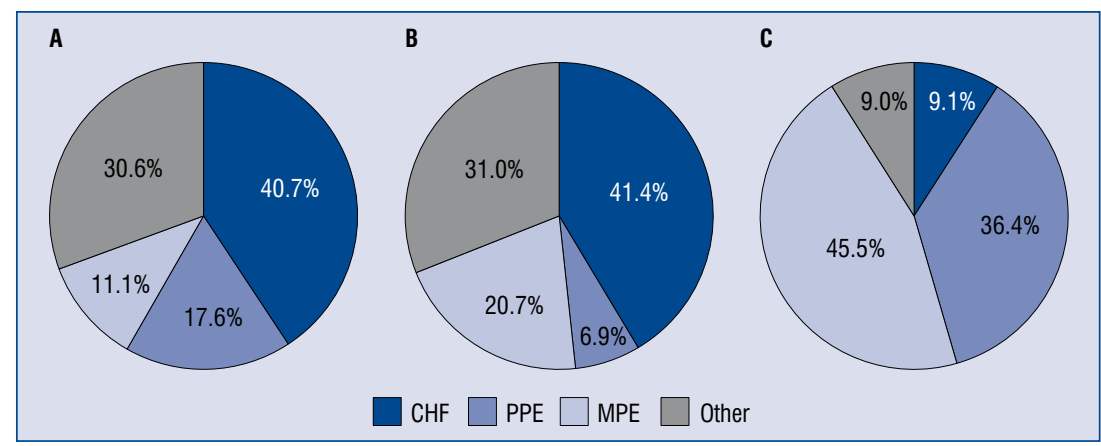

Figure 2. Distribution of underlying causes of pleural fluid formation in patients with small $(n=158 ; A)$, moderate $(n=28 ; B)$ and large $(n=14 ; C)$ volume of pleural effusion; CHF — congestive heart failure; MPE — malignant pleural effusion; PPE — parapneumonic pleural effusion.

$(\mathrm{p}=0.24)$ and $21.8 \%$ lower than in MPE $(\mathrm{p}=0.027)$. Comparative analysis of patients with the most common causes of pleural exudate did not reveal significant differences in terms of gender distribution and 30-day mortality. Patients with TPE were significantly younger than patients with PPE, $\mathrm{p}=0.024$. There was also a relevant (although statistically insignificant) difference between the age of TPE and PPE patients (Table 1).

The vast majority of patients $(n=153)$ presented with small volume of pleural fluid. The most common causes of PE in patients with small amount of fluid were CHF 40.7\%, PPE (17.6\%), and MPE (11.1\%), $\mathrm{p}<0.0001$ (Fig. 2). Similarly, in patients with moderate volume pleural effusion CHF (41.4\%) was also the most common underlying disease, followed by MPE (20.7\%), and PPE $(6.9 \%), p=0.02$. There were only 14 patients with large volume pleural effusion and the differences between the number of patients with other underlying diseases did not reach statistical significance.

There was a significantly uneven distribution of $\mathrm{PE}$ volume in patients with $\mathrm{CHF}$ and $\mathrm{PPE}$, with a marked predominance (77.2\%) of small volume of pleural fluid. Even though over half of the patients with MPE were found to have a small amount of $\mathrm{PE}, 47.8 \%$ of these patients had a moderate to large volume of pleural fluid (Fig. 3).

The prevalence of CHF, MPE and PPE in relation to pleural fluid volume and its localization (unilateral or bilateral) is shown in Table 2 .

\section{Discussion}

The present analysis of chest radiographs and medical records of almost 2000 patients treated in one of the largest multidisciplinary hospitals in Poland showed that PE was present in $10.1 \%$ of patients. The most common cause of PE was heart failure (37.4\%), followed by parapneumonic $(19.5 \%)$ and malignant (15.4\%) effusion. Importantly, CHF alone was responsible for a number of cases comparable to the summed number of cases caused by the three other of the most common entities associated with $\mathrm{PE}$, i.e. parapneumonic pleural effusion, pleural malignancies and hepatic hydrothorax (73 vs. 76 patients, respectively). Thus, these results emphasize the role of $\mathrm{CHF}$ as 


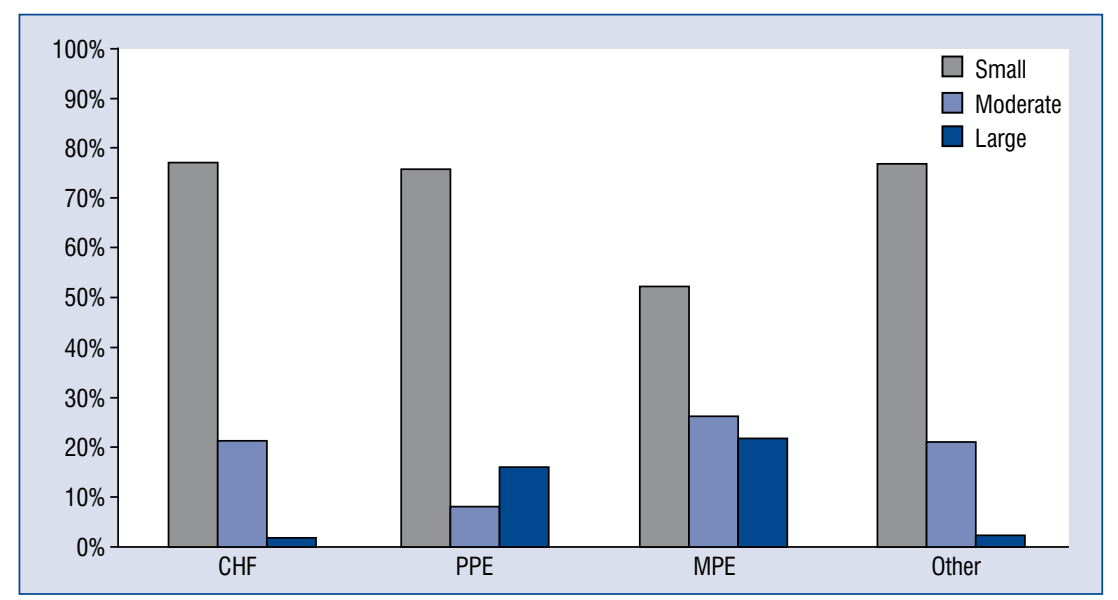

Figure 3. Differences between distribution of pleural fluid volume in patients with various causes of pleural effusion; CHF — congestive heart failure; MPE — malignant pleural effusion; PPE — parapneumonic pleural effusion.

Table 2. The percentage of patients with unilateral and bilateral pleural effusion and various effusion causes (congestive heart failure, parapneumonic effusion and malignant pleural effusion) in relation to pleural fluid volume (small, moderate and large). Percentages form $100 \%$ in each pleural fluid volume category (small, moderate and large).

\begin{tabular}{|c|c|c|c|c|c|c|c|c|c|}
\hline & \multicolumn{9}{|c|}{ Pleural fluid volume } \\
\hline & \multicolumn{3}{|c|}{ Small } & \multicolumn{3}{|c|}{ Moderate } & \multicolumn{3}{|c|}{ Large } \\
\hline & UL & B & $\mathbf{p}$ & UL & B & $\mathbf{p}$ & UL & B & $\mathbf{p}$ \\
\hline $\mathrm{CHF}$ & $28 \%$ & $31 \%$ & & $30 \%$ & $30 \%$ & & $10 \%$ & $0 \%$ & \\
\hline PPE & $17 \%$ & $8 \%$ & 0.05 & $5 \%$ & $5 \%$ & 0.79 & $30 \%$ & $10 \%$ & 0.85 \\
\hline MPE & $13 \%$ & $3 \%$ & & $20 \%$ & $10 \%$ & & $40 \%$ & $10 \%$ & \\
\hline
\end{tabular}

B — bilateral; CHF — congestive heart failure; MPE — malignant pleural effusion; PPE — parapneumonic pleural effusion; UL — unilateral

the most common underlying disease in patients with $\mathrm{PE}$ and indicate that $\mathrm{CHF}$ should be a major differential diagnosis in these patients. It was also observed that almost $80 \%$ of patients with $\mathrm{CHF}$ presented with only a small volume PE.

According to available research, this is the most recent and one of the very few studies from Central or Eastern Europe presenting epidemiological data on the causes of PE. In fact, the previous study which evaluated the incidence of $\mathrm{PE}$ in a well-defined region of Central Bohemia was published 25 years ago. Although there were numerous differences between the current study and a study by Marel et al. [14], both studies showed that CHF was, and still is, the most common cause of $\mathrm{PE}$ in Central Europe.

Several important studies on the causes of PE have been performed in other countries and world regions. In 2014, Porcel et al. [2] published the results of a Spanish study which included data on 3007 patients who underwent diagnostic thoracentesis during the previous 19 years. The authors found that the most common cause of pleural fluid were pleural malignancies $(27.3 \%)$, while heart failure was the second leading cause responsible for $20.8 \%$ of cases [2]. Chronic heart failure is believed to be the most common cause of PE in the United States. The estimated annual incidence of various causes of PE in this country showed that $\mathrm{CHF}$ was responsible for $36.3 \%$ of cases [1]. Pleural effusion associated with $\mathrm{CHF}$ was 1.7 and 2.5-fold more common than PPE and MPE, respectively [1]. The differences between the results of various studies are multifactorial and were related not only to local epidemiological situations and study group characteristics, but also to the definitions and methods used in the particular studies. For instance, only patients who underwent diagnostic thoracentesis were included in the study by Porcel et al. [2]. This obviously may result in selection 
Table 3. Comparison of data on causes of pleural effusion presented by various authors.

\begin{tabular}{lccc}
\hline Disease & $\begin{array}{c}\text { Light et al. [1] } \\
\text { (2011) }\end{array}$ & $\begin{array}{c}\text { Porcel et al. [2] } \\
\text { (2014) }\end{array}$ & $\begin{array}{c}\text { Korczynski et al. } \\
\text { (current study) }\end{array}$ \\
$\mathbf{N}=\mathbf{3 0 7 7}=\mathbf{1 9 5}$
\end{tabular}

CABG — coronary artery bypass grafting; NA — not applicable

bias, as according to common guidelines, not all patients with $\mathrm{PE}$ due to heart failure require diagnostic thoracentesis [15]. On the other hand, a high level of agreement between different studies in terms of the three most common causes of $\mathrm{PE}$ should be noted. The numerical data found in the present study is fully consistent with United States data published by Light [1]. To show this agreement, data from three different publications are presented in Table 3.

A significant proportion of patients with $\mathrm{PE}$ due to CHF may have various practical implications. Although a diagnostic thoracentesis to differentiate between transudate and exudate is necessary only in a small proportion of these patients, the high overall number of patients with $\mathrm{PE}$ due to CHF may result in a significant number of patients undergoing the procedure. In this context, it should be remembered that Light's criteria were commonly applied to differentiate between transudate and exudate and were only moderately specific for exudate. Hence, even more than $20 \%$ of transudates (mainly due to CHF) can be incorrectly classified as exudates [16]. Therefore, additional criteria distinguishing between pleural transudate and exudate have been proposed for patients with suspicion of CHF-related PE which was classified as exudate by Light's criteria. These include pleural fluid-serum albumin gradient and pleural fluid or serum N-terminal pro-B-type natriuretic peptide levels [17-19]. It should also be noted that, in spite of a high diagnostic sensitivity of Light's criteria for $\mathrm{PE}$, some MPEs can be diagnosed as transudates.
In a study by Ferreiro et al. [20] 26/281 (9.3\%) of pleural transudates were caused by malignancies.

Due to the anatomical and functional relationships, $\mathrm{PE}$ in patients with CHF is mainly related to left ventricular failure. Also, the number of patients with left ventricular dysfunction or dysfunction of both ventricles is significantly higher than the number of patients with right ventricular failure [21]. Therefore, in daily clinical practice, the vast majority of PEs in patients with CHF is related to left ventricular dysfunction. Nonetheless, PE may also be associated with right ventricular failure. Tang et al. [22] found PE in 19 of 147 patients (13\%) with isolated right heart failure due to idiopathic or familial pulmonary hypertension.

The prevalence of PE depends on the sensitivity of methods used to detect pleural fluid. As the majority of patients with CHF-related PE have small volume effusions, the sensitivity of imaging methods may significantly affect the results of studies on $\mathrm{PE}$ in CHF. It has been shown that plain chest radiograph (CXR) revealed PE only in $25 \%$ of patients in a series of 447 patients with heart failure [23]. On the other hand, the use of more sensitive tools, such as computed tomography, ultrasound or autopsy resulted in a much higher reported PE prevalence (even more than 80\%) [24-26].

As mentioned above, the volume of CHF-related $\mathrm{PE}$ is usually small. This was also the case in the present study. More than $77 \%$ of patients with PE due to $\mathrm{CHF}$ presented with only small volume of pleural fluid. These results are consistent with data published by Porcel and Vives [27]. 
In the current study $51 \%$ of patients with $\mathrm{PE}$ due to CHF presented with bilateral pleural fluid. This number is lower than that reported in previous studies. Woodring et al. [28] found bilateral pleural involvement in $72.5 \%$ of patients with pleural effusion due to CHF. Also, the study by Porcel and Vives [27] published in 2006 showed virtually the same percentage of patients with bilateral pleural effusion $(70 \%)$. On the other hand, later studies by Porcel [29] and de Araujo et al. [30] reported that the percentages of patients with bilateral PE were only slightly higher than demonstrated in the present study ( $61 \%$ and $51 \%$, respectively). Again, the differences between the results of these studies can probably be largely attributed to methods of pleural fluid detection.

In the present study, 30-day mortality rate in patients with various causes of $\mathrm{PE}$ ranged from $0 \%$ to $40 \%$. Thirty-day mortality rate for CHF was $19.2 \%$. This number seems to be high when compared to data published by Maggioni et al. [31] or Tyminska et al. [32]. These authors reported 1-year mortality rate in all patients admitted to hospital for acute $\mathrm{HF} 17.4 \%$ and $13-21 \%$, respectively. However, there were many differences between the studies that may have been responsible for the fact that the 30-day mortality rate in the current study was not comparable to 1-year mortality rate in studies by Maggioni et al. [31] and Tyminska et al. [32]. These include a primarily lower age with a median of 71 (IQR 61-79) years and selection of all patients with acute HF. What is worth emphasizing, pulmonary congestion was an independent predictor of all-cause 1-year mortality with a hazard ratio (95\% confidence interval): 2.73 (1.71-4.35) [31]. It is suspected that the present results remain in agreement with previously cited studies and the presence of $\mathrm{PE}$ in heart failure patients is a negative prognostic factor.

\section{Limitations of the study}

There are some limitations in the present study. First, data for analysis were collected from only 1 month during winter. Hence, although the total number of patients in whom CXR was performed was almost 2000, the number of patients with PE was relatively low in the context of an epidemiological study [31]. Furthermore, there might have been a bias in the true annual proportion of patients with different causes of PE related to seasonal infections [33]. Second, CXR was the only tool to select patients with PE. It may be supposed that the use of more sensitive tools could have resulted in an even higher percentage of patients with a diagnosis of small volume PE. Third, this study included only hospitalized patients. This probably refers also to patients with CHF, as many of these patients did not require diagnostic thoracentesis and could have been be treated as outpatients [34]. Finally, the present results could have been affected by the profile of hospital departments and predominating spectrum of their patients.

\section{Conclusions}

Pleural effusion was found in $10.1 \%$ of patients treated in a large multidisciplinary hospital. CHF was responsible for $37.4 \%$ of all cases. Almost $80 \%$ of patients with CHF-related PE presented with only a small volume of pleural fluid. Although 30-day mortality in patients with CHF with $\mathrm{PE}$ was relatively high, it was lower than that in PPE and MPE.

\section{Conflict of interest: None declared}

\section{References}

1. Light RW. Pleural effusions. Med Clin North Am. 2011; 95(6): 1055-1070, doi: 10.1016/j.mcna.2011.08.005, indexed in Pubmed: 22032427.

2. Porcel JM, Esquerda A, Vives M, et al. Etiology of pleural effusions: analysis of more than 3,000 consecutive thoracenteses. Arch Bronconeumol. 2014; 50(5): 161-165, doi: 10.1016/j.arbres.2013.11.007, indexed in Pubmed: 24360987.

3. Baumann MH, Nolan R, Petrini M, et al. Pleural tuberculosis in the United States: incidence and drug resistance. Chest. 2007; 131(4): 1125-1132, doi: 10.1378/chest.06-2352, indexed in Pubmed: 17426219.

4. Porcel JM. Advances in the diagnosis of tuberculous pleuritis. Ann Transl Med. 2016; 4(15): 282, doi: 10.21037/atm.2016.07.23, indexed in Pubmed: 27570776.

5. Mortazavi-Moghaddam SG, Sharifzadeh GR, Rezvani MR. Status of Exudative Pleural Effusion in Adults of South Khorasan Province, Northeast Iran: Pleural Tuberculosis Tending toward Elderly. Iran J Med Sci. 2016; 41(4): 322-327, indexed in Pubmed: 27365554.

6. Rafiee S, Besharat S, Jabbari A, et al. Epidemiology of tuberculosis in Northeast of Iran: a population-based study. Iran J Med Sci. 2015; 34(3): 193-197.

7. U.S. Cancer Statistics Working Group. U.S. Cancer Statistics Data Visualizations Tool, based on November 2017 submission data (1999-2015): U.S. Department of Health and Human Services, Centers for Disease Control and Prevention and National Cancer Institute;. www.cdc.gov/cancer/dataviz(Accessed June 2018).

8. Murphy SL, Xu J, Kochanek KD, et al. Deaths: Final Data for 2015. Natl Vital Stat Rep. 2017; 66(6): 1-75.

9. Cierniak-Piotrowska M, Marciniak G, Stanczuk J. Statystyka Zgonow i Umieralnosci Z Powodu Chorob Układu Krazenia. In: Strzelecki Z, Szymborski J, editors. Zachorowalnosc i umieral- 
nosc na choroby ukladu krazenia a sytuacja demograficzna Polski: Rzadowa Rada Ludnosci. 2015.

10. Korzeniowska-Kosela M. Gruzlica w Polsce w 2016 roku. Biuletyn IGiChP. 2016.

11. Didkowska J, Wojciechowska U. Zachorowania i zgony na nowotwory zlosliwe w Polsce. Krajowy Rejestr Nowotworow, Centrum Onkologii - Instytut im. Marii Sklodowskiej-Curie. http://onkologia.org.pl/k/epidemiologia (Accesed June 2018).

12. Krenke R, Nasilowski J, Korczynski P, et al. Incidence and aetiology of eosinophilic pleural effusion. Eur Respir J. 2009; 34(5): 1111-1117, doi: 10.1183/09031936.00197708, indexed in Pubmed: 19386682 .

13. Klimiuk J, Krenke R, Safianowska A, et al. Diagnostic performance of different pleural fluid biomarkers in tuberculous pleurisy. Adv Exp Med Biol. 2015; 852: 21-30.

14. Marel M, Zrůstová M, Stasný B, et al. The incidence of pleural effusion in a well-defined region. Epidemiologic study in central Bohemia. Chest. 1993; 104(5): 1486-1489, indexed in Pubmed: 8222812.

15. Hooper C, Lee YC, Maskell N. Investigation of a unilateral pleural effusion in adults: British Thoracic Society Pleural Disease Guideline 2010. Thorax. 2010; 65 Suppl 2: ii4-i17, doi: 10.1136/ /thx.2010.136978, indexed in Pubmed: 20696692.

16. Porcel JM. Pearls and myths in pleural fluid analysis. Respirology. 2011; 16(1): 44-52, doi: 10.1111/j.1440-1843.2010.01794.x, indexed in Pubmed: 20573057.

17. Bielsa S, Porcel JM, Castellote J, et al. Solving the Light's criteria misclassification rate of cardiac and hepatic transudates. Respirology. 2012; 17(4): 721-726, doi: 10.1111/j.14401843.2012.02155.x, indexed in Pubmed: 22372660.

18. Han ZJ, Wu XD, Cheng JJ, et al. Diagnostic Accuracy of Natriuretic Peptides for Heart Failure in Patients with Pleural Effusion: A Systematic Review and Updated Meta-Analysis. PLoS One. 2015; 10(8): e0134376, doi: 10.1371/journal.pone.0134376, indexed in Pubmed: 26244664.

19. Porcel J. Identifying transudates misclassified by Light's criteria. Current Opinion in Pulmonary Medicine. 2013; 19(4): 362-367, doi: 10.1097/mcp.0b013e32836022dc.

20. Ferreiro L, Gude F, Toubes ME, et al. Predictive models of malignant transudative pleural effusions. J Thorac Dis. 2017; 9(1): 106-116, doi: 10.21037/jtd.2017.01.12, indexed in Pubmed: 28203412.

21. Ponikowski P, Voors A, Anker S, et al. 2016 ESC Guidelines for the diagnosis and treatment of acute and chronic heart failure: The Task Force for the diagnosis and treatment of acute and chronic heart failure of the European Society of Cardiology (ESC). Developed with the special contribution of the Heart Failure Association (HFA) of the ESC. Eur J Heart Fail. 2016; 18(8): 891-975, doi: 10.1002/ejhf.592.

22. Tang KJ, Robbins IM, Light RW. Incidence of pleural effusions in idiopathic and familial pulmonary arterial hypertension patients.
Chest. 2009; 136(3): 688-693, doi: 10.1378/chest.08-0659, indexed in Pubmed: 19395582.

23. Knudsen CW, Omland T, Clopton P, et al. Diagnostic value of B-Type natriuretic peptide and chest radiographic findings in patients with acute dyspnea. Am J Med. 2004; 116(6): 363-368, doi: 10.1016/j.amjmed.2003.10.028, indexed in Pubmed: 15006584

24. Kataoka H. Pericardial and pleural effusions in decompensated chronic heart failure. Am Heart J. 2000; 139(5): 918-923, indexed in Pubmed: 10783228.

25. Kataoka H, Takada S. The role of thoracic ultrasonography for evaluation of patients with decompensated chronic heart failure. J Am Coll Cardiol. 2000; 35(6): 1638-1646, indexed in Pubmed: 10807471.

26. Edwards JE, Race GA, Scheifley CH. Hydrothorax in congestive heart failure. Am J Med. 1957; 22(1): 83-89, indexed in Pubmed: 13381740.

27. Porcel JM, Vives M. Distribution of pleural effusion in congestive heart failure. South Med J. 2006; 99(1): 98-99, doi: 10.1097/01. smj.0000199278.81401.2f, indexed in Pubmed: 16466136.

28. Woodring LA, Cancelli AA, Ponterotto JG, et al. A qualitative investigation of adolescents' experiences with parental HIV/AIDS. Am J Orthopsychiatry. 2005; 75(4): 658-675, doi: 10.1037/00029432.75.4.658, indexed in Pubmed: 16262522.

29. Porcel J. Pleural effusions from congestive heart failure. Semin Respir Crit Care Med. 2011; 31(06): 689-697, doi: 10.1055/s0030-1269828.

30. de Araujo BS, Reichert R, Eifer DA, et al. Trepopnea may explain right-sided pleural effusion in patients with decompensated heart failure. Am J Emerg Med. 2012; 30(6): 925-931.e2, doi: 10.1016/j.ajem.2011.04.013, indexed in Pubmed: 21665407.

31. Maggioni AP, Dahlström U, Filippatos G, et al. EURObservational Research Programme: regional differences and 1-year followup results of the Heart Failure Pilot Survey (ESC-HF Pilot). Eur J Heart Fail. 2013; 15(7): 808-817, doi: 10.1093/eurjhf/hft050, indexed in Pubmed: 23537547.

32. Tymińska A, Kapłon-Cieślicka A, Ozierański K, et al. Anemia at Hospital Admission and Its Relation to Outcomes in Patients With Heart Failure (from the Polish Cohort of 2 European Society of Cardiology Heart Failure Registries). Am J Cardiol. 2017; 119(12): 2021-2029, doi: 10.1016/j.amjcard.2017.03.035, indexed in Pubmed: 28434647.

33. Kim ES, Park KU, Lee SH, et al. Comparison of viral infection in healthcare-associated pneumonia (HCAP) and community-acquired pneumonia (CAP). PLoS One. 2018; 13(2): e0192893, doi: 10.1371/journal.pone.0192893, indexed in Pubmed: 29447204.

34. Mirra M, Vitulano G, Virtuoso N, et al. Heart Failure in a Dedicated Outpatient Clinic: Results after 58 Month Follow-Up. Can it be Enough? Transl Med UniSa. 2015; 11: 59-62, indexed in Pubmed: 25674552 